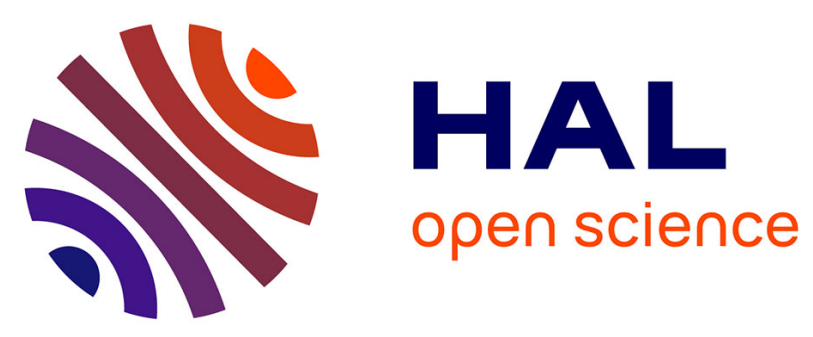

\title{
Real-time method for the identification and quantification of hydrocarbon pyrolysis products: Part I. Development and validation of the infra red technique
} Grégory Abraham, Nicolas Gascoin, Philippe Gillard, Marc Bouchez

\section{- To cite this version:}

Grégory Abraham, Nicolas Gascoin, Philippe Gillard, Marc Bouchez. Real-time method for the identification and quantification of hydrocarbon pyrolysis products: Part I. Development and validation of the infra red technique. Journal of Analytical and Applied Pyrolysis, 2011, 91 (2), pp.368-376. 10.1016/j.jaap.2011.03.014 . hal-00641587

\section{HAL Id: hal-00641587 \\ https://hal.science/hal-00641587}

Submitted on 17 Nov 2011

HAL is a multi-disciplinary open access archive for the deposit and dissemination of scientific research documents, whether they are published or not. The documents may come from teaching and research institutions in France or abroad, or from public or private research centers.
L'archive ouverte pluridisciplinaire HAL, est destinée au dépôt et à la diffusion de documents scientifiques de niveau recherche, publiés ou non, émanant des établissements d'enseignement et de recherche français ou étrangers, des laboratoires publics ou privés. 
Real-time method for the identification and quantification of hydrocarbon pyrolysis products:

Part I. Development and validation of the Infra Red technique.

$$
\text { Gregory Abraham }{ }^{\mathrm{a}}, \text { Nicolas Gascoin }^{\mathrm{a} 1}, \text { Philippe Gillard }^{\mathrm{a}}, \text { Marc Bouchez }^{\mathrm{b}}
$$

${ }^{a}$ PRISME Institute, University of Orléans

63, avenue de Lattre de Tassigny, 18020 Bourges Cedex, France

\author{
${ }^{\mathrm{b}}$ MBDA France \\ 8, rue Le Brix, 18000 Bourges, France
}

\begin{abstract}
Due to large heat load encountered in high speed flight (over Mach 5), the regenerative cooling of the engine leads to the study of the endothermic pyrolysis of the onboard hydrocarbon fuel, which acts as a coolant. However the control and regulation of such a technology implies to have a correct knowledge of the endothermic pyrolysis of the onboard hydrocarbon fuel, which motivates the development of a quantitative measuring method adapted to in-flight applications. A Fourier Transform Infra Red spectrometer is used and a specific method has been developed to identify and to quantify the major hydrocarbon products of the pyrolysis. The technique is validated and tested at the outlet of the experimental pyrolysis process which operates under steady-state conditions from $823 \mathrm{~K}$ to $1023 \mathrm{~K}$ and up to 60 bar. Two mass flow rates $\left(0.05 \mathrm{~g} . \mathrm{s}^{-1}\right.$ and $\left.0.1 \mathrm{~g} . \mathrm{s}^{-1}\right)$ are studied with titanium reactor to determine the limits of validity and to improve the method. Several synthetic and jet fuels have been tested (heptane, decane, dodecane and two kerosenes). The
\end{abstract}

\footnotetext{
1 Corresponding author. Tel.: +33.248.238.473; fax: +33.248 .238 .871 . E-mail address: Nicolas.Gascoin@bourges.univ-orleans.fr (N. Gascoin)
} 
quantities of five light hydrocarbons (methane, ethane, ethylene, propane, propylene) are determined. The method, based on classical least square processing, is validated with respect to gas chromatograph (and mass spectrometer) analysis notably. A minimum molar fraction of 5 mol.\% can be obtained and the accuracy is better than 2 mol.\%.

\section{Keywords}

Hydrocarbon pyrolysis; Fourier Transform Infra Red Spectrometer; Gas Chromatograph-Mass Spectrometer; supercritical state; coke.

\section{Introduction}

Ramjet and SCRamjet (Supersonic Combustion Ramjet) engines cover a large range of flight speed (from Mach 2 to Mach 12) [1]-[4]. These air-breathing technologies capture and geometrically compress external air to be burned after fuel injection. The combustion can be achieved under subsonic regime (flight Mach number less than 5 with Ramjet) or supersonic one (over Mach 5, SCRamjet). Due to high flight speed and combustion, the temperature is so high (up to $4500 \mathrm{~K}$ ) that the vehicle's structure starts to be damaged. It is generally composed of a carbon/carbon $(\mathrm{C} / \mathrm{C})$ composite or Ceramic Matrix Composite (CMC), which allow withstanding high heat loads (around $2000 \mathrm{~K}$ ) [5]. Nevertheless, it is necessary to use a cooling system for the SCRamjet [6].

\subsection{Fuel cooled structures}

The regenerative cooling technique uses the fuel as a coolant (it flows in a surrounding channel around the combustion chamber), which is then burned to ensure the thrust [7]. Due to the high pressure in the cooling channel, the fuel can reach a supercritical state (high temperature and high pressure). Then, pyrolysis appears for temperature generally over $800 \mathrm{~K}$ and the thermal energy of the hot wall is converted into chemical energy [8]. The 
decomposition generates products which will be injected in the combustion chamber. Having a clear knowledge of the pyrolysis phenomenon becomes very important to understand how the chemical reactions absorb the thermal energy. The nature of chemical species which are generated by these reactions must be determined. Knowing what their respective quantities are enables to estimate their burning efficiency and, as a consequence, it allows controlling the overall hypersonic cooled system. This regenerative cooling technology presents some problems related to formation of unknown species (except if some measuring technique is available) and coke formation (reduction of mass flow and consequently difficulty to manage the thrust) [9]. Consequently, measuring some parameters such as the fuel composition and flow rate before injection -and their temporal evolution- is necessary. The chemical composition is important to provide information in order to control the combustion in the engine and the cooling efficiency. Online and onboard transient measurements must be proposed.

\subsection{Hydrocarbons pyrolysis and analytical measuring techniques}

The COMPARER project (a French acronym for COntrol and Measure of PArameters in a REacting stReam) has been undertaken by the University of Orléans and by MBDA-France. During the COMPARER-1 project (2003-2006), an experimental bench has been established for the study of fuel pyrolysis [9]. It allows reaching supercritical state in a reactor (usually stainless steel 316L or titanium) with a constant mass flow. Maximum operating parameters are about $1800 \mathrm{~K}, 8 \mathrm{MPa}$ and $0.6 \mathrm{~g} . \mathrm{s}^{-1}$. The different parts of the COMPARER setup will be described in section 2.1. The n-dodecane pyrolysis has been conducted over the past years with constant temperature (from $600 \mathrm{~K}$ to $1100 \mathrm{~K}$ ) under steady-state conditions. The pyrolysis products were quantified by Gas Chromatography (GC) coupled with a Flame Ionisation Detector (FID). A numerical simulation tool has been developed [9] and the coke formation was investigated [11]. The COMPARER-2 project covers the period 2006-2009. 
Numerous studies are available on fuel pyrolysis, with various types of fluid nature, operating conditions and nature of reactor walls. A brief survey will help proposing an optical quantification method to know which main products should be monitored. Light species (gaseous at ambient conditions) are generally the major ones in the pyrolysis mixtures. Concerning n-heptane, Pant and Kunzru [12] have studied its pyrolysis at ambient pressure up to $1023 \mathrm{~K}$ under diluted condition in water. The major species are methane, ethylene, propylene and butene. Of course, the relative quantities of each species vary (not linearly) with the temperature increase. Some species are formed and then consumed. Chakraborty and Kunzru [13] studied heptane diluted in Argon with residence time up to $15 \mathrm{~s}$ and pressure of 2.9 MPa. Wang et al. [14] conducted pyrolysis under undiluted supercritical state (3.5 MPa and $923 \mathrm{~K}$ maximum). The same decomposition products are found. Garner et al. [15] used a shock tube at elevated pressure and temperature $(50$ bar, $1350 \mathrm{~K})$ for low residence time (less than $3 \mathrm{~ms}$ ). The pyrolysis products are mainly light alkenes (gaseous at ambient conditions).

N-Decane has been less studied. Zeppieri et al. [16] found as major compounds: methane, ethylene, propylene and butene up to $1050 \mathrm{~K}$ at ambient pressure (residence time up to $0.3 \mathrm{~s}$ ) while Rocourt et al. [17],[18] found mostly hydrogen, methane, ethylene, propylene and benzene. The results are summarized in Table 1.

\section{Table 1 should be placed here}

N-dodecane has been studied by Gascoin et al. [19] in open tubular reactor under sub-and supercritical state and undiluted conditions (up to $6 \mathrm{MPa}$ and $1225 \mathrm{~K}$ ) with residence time less than 200 s. Hydrogen, methane and the alkane-alkene couples from $C_{2}$ to $C_{4}$ were found in majority for large pyrolysis rate (up to $100 \%$ ). Herbinet et al. [20] used a premixed quartz reactor with residence time less than $5 \mathrm{~s}$ at ambient pressure with dilution in helium. A similar composition of the pyrolysis products was observed. Dahm et al. [10] used similar conditions as those of Herbinet. The results are summarized in Table 2. 
The kerosene pyrolysis is more difficult to study because it is composed of numerous species and additives. Yu and Eser [21] studied hydrocarbon mixtures under supercritical state and Wang et al. [22] studied a kerosene-like mixture. The pyrolysis products are also light species from hydrogen to propane roughly.

\section{Table 2 should be placed here}

Consequently, the quantification method to be developed in the framework of the COMPARER project and presented in this paper should focus on light species like hydrogen, methane, ethylene, ethane, propylene and propane. These compounds are the major species produced for high pyrolysis rate. Large decomposition rates are found for SCRamjet engine cooling because it has been shown in previous work that the pyrolysed fuel mixture reaches $1500 \mathrm{~K}$ before injection in the combustion chamber [9]. For this purpose, it can be interesting to observe the available techniques and determine if one is already suitable for this purpose (Table 3).

Analytical tools generally used for this kind of experiment are: chromatography or mass spectrometry (MS) [23]. The electrochemical methods are mainly suited for hydrogen with strong thermal conductivity difference in comparison with hydrocarbons, all with similar conductivity. The electronic methods [24] make no clear difference between different hydrocarbons. This is the same for the Flame Ionisation Detector, the Thermal Conductivity Detector and the Mass Spectrometer without preliminary separation (not possible for onboard application). The optical diagnostics are of larger interest because they are not intrusive. The Infra-Red and Ultra-Violet spectroscopic techniques are easier to apply [25] in comparison to Raman spectrometry [26] or Atomic Absorption method [27], especially for flight automated application. The Ultra-Violet technique is suitable for hydrogen but not for hydrocarbons [28]. Consequently, the FTIR spectrometry technique has been retained for the COMPARER2 project. Some attempts to quantify hydrocarbons by FTIR have been reported. Descamps et 
al. [29] used it to quantify in situ aromatic compounds under lab conditions. Feron et al. [30] used the same equipment on chlorinated compounds in mixture with hydrocarbons, which multiplies the chemical bonds, thus the quantification feasibility. Nevertheless, no dedicated quantification method was proposed and the absorbance signal was purely observed as a function of temperature. Three advantages and three drawbacks of FTIR spectrometry are respectively:

- High measurement frequency (over one spectrum per second depending on the spectral range and on the detector)

- Non intrusive technique

- Very robust and highly reliable (no loss of accuracy after calibration)

- Not accurate in speciation (based on signal of chemical bonds which are similar for all the hydrocarbons)

- Difficult to adjust (loss of signal or rapid saturation depending on the concentration of species)

- No hydrogen detection

\section{Table 3 should be placed here}

The purpose of the COMPARER-2 project (2006-2009) is the analysis of pyrolysis products in transient conditions under supercritical state with an upgraded bench (FTIR, GC/MS and other automated devices). On the basis of Table 3, the previous COMPARER experimental pyrolysis bench has been augmented by insertion of an FTIR spectrometer (NICOLET 6700), which allows measuring in real time the fuel composition generated during the pyrolysis of $\mathrm{n}$-dodecane and other fuels.

The quantification method which is developed for a hypersonic application should meet the following requirements: one measurement per $10 \mathrm{~s}$, an accuracy less than 5 mol. $\%$ for main products and a quantification of at least $75 \mathrm{~mol} \%$ of the mixture. The purpose of this 
paper is to present the FTIR method developed for the measurement of the pyrolysis products composition and to validate it with gas chromatography/mass spectrometry (GC/MS). In section 2, the experimental bench is described as well as the data processing method .In section 3 , the validation of the method under no flow and open flow conditions is presented with estimation of the uncertainties and limitations of the method.

\section{Pyrolysis test bench and conception of the FTIR method}

\subsection{Experimental apparatus}

The COMPARER bench has been upgraded since the version presented in [9]. The dead volume is largely reduced, a new method for the separation of gas and liquid pyrolysis products (at ambient conditions) enables dynamic sampling for transient studies, a GC-MS and an FTIR are now available. A schematic of the bench is given in Figure 1. A volumetric pump (LEWA, FCMk1 with a HYDRACAR pulsation attenuator) imposes a "constant" mass flow in the system, which is measured by a Coriolis mass flow meter (Elite CMF010M, Micromotion). All the tubes of the bench (Swagelok, $1.4 \mathrm{~mm}$ inner diameter and $3.2 \mathrm{~mm}$ outer diameter) are made of stainless steel. Two reactor vessels furnished by Swagelok (Stainless Steel 316L and Titanium, $1 \mathrm{~m}$ long, $4.5 \mathrm{~mm}$ inner diameter, $6.4 \mathrm{~mm}$ outer diameter) can be placed (one or another) in an oven (Carbolite, STF16-450B, Recrystalised Alumina RCA- tube, temperature regulator Eurotherm 3216P5) to conduct the pyrolysis. Seven thermocouples (six K type and one R type) are disposed in the RCA tube (where the pyrolysis reactor is also placed) to measure the temperature in different points of the reactor. Downstream and upstream the reactor, two pressure transducers (Rosemount, 2088A) measure the process pressure and enable detection of jamming up in case of coke formation. A water cooled heat exchanger reduces the temperature of outlet pyrolysis products down to the ambient temperature. A downstream controller (Samson, 994-0050) regulates the process 
pressure and the decomposition mixture is brought to atmospheric pressure. A liquid/gas phase separator enables a dynamic sampling of liquid and gas products for later analysis of the separate phases. Three paths for gases are available, the main one for gas evacuation toward a burner (for safety reasons and for combustion study), one toward a coupled GC-MS apparatus and one toward an FTIR spectrometer. Four mass flow meters (one Coriolis and three volumetric flow meters) monitor the mass flow in these three lines to enable transient mass balance. The pressures of GC-MS and FTIR lines are automatically regulated with negative relative value (absolute pressure of 950 mbar and 50 mbar respectively) with two vacuum pumps (KNF, membrane pumps). The synthetic fuels are furnished by VWR Prolabo (Rectapur quality, over $99.95 \%$ purity) and the jet fuels are provided by MBDA-France. The gases of GC-MS are provided by Air Liquide (Alphagas 2 quality for Hydrogen and Helium, Alphagas 1 quality for Nitrogen and Air). Nitrogen (Air Liquide, U Quality) is also used to clean the reactor and all the tubing at the end of the experiment (decrease of temperature, removal of any coke particles and of remaining liquid or gas products).

\section{Figure 1 should be placed here}

The GC (Varian, 3800 with Varian MS Workstation 6.9 software) is equipped with a flame ionisation detector (FID), a thermal conductivity detector (TCD) and a Mass Spectrometer (Varian, Saturn 4000 with ion trap). Several columns are used for the separation of the gas compounds depending on the detector (Varian, Haysep-Q, Molsieve 13X and Porabond Q). A CPSil-5 CB column (Varian) separates the liquid compounds. All the three detectors and two carrier gases (helium and nitrogen) are used simultaneously. The detailed setting of GC and MS can be found in [23]. The FTIR (Thermofisher, Nicolet 6700) is equipped with a DTGS detector and a KBr beamsplitter. The Omnic and TQ Analyst software are used for signal acquisition and processing. The optical gas cell placed inside the FTIR (optical path length of $10 \mathrm{~cm}$ ) has a volume of $100 \mathrm{~cm}^{3}$. The FTIR method developed and 
presented in this paper (focusing on pyrolysis gas products such as methane, ethane, propane, ethene, and propene) will thus be validated with respect to GC-MS results.

\subsection{Infra Red technique and associated quantification method}

The main advantage of the FTIR technique is a high data acquisition frequency (one measure per $1 \mathrm{~s}$ to $10 \mathrm{~s}$ roughly) in comparison with GC-MS (about one quantification of the chemical composition per hour). It is a non-intrusive method but with limited quantification ability because the IR signal (absorbance vs. wavenumber) comes from chemical bonds (vibration, rotation, stretching), which are quite the same for all common pyrolysis products (simple, double and triple carbon-carbon bonds and carbon-hydrogen bond generally). For this reason, this work will focus on only five species (selected on the basis of previous pyrolysis state of art), which are gaseous at ambient conditions. The interest of the developed method is to be able to extract the signal related to each of these species and to link it to their quantity in the mixture (mole or mass fraction).

A preliminary work is required to calibrate the FTIR and to design the data processing method. The conditions of measure have been carefully chosen to get the best accuracy during quantification of calibrated gas samples. The resolution $\left(0.5 \mathrm{~cm}^{-1}\right)$, the number of scans (32) and other internal parameters (scan velocity, $\mathrm{H}_{2} \mathrm{O}$ and $\mathrm{CO}_{2}$ corrections, background,...) have been justified [23] and the temperature (373 $\mathrm{K}$ to avoid water condensation notably) and absolute pressure (50 mbar) in the optical gas cell also. This pressure avoids the saturation of the detector if non diluted pure single species is measured. These parameters are those used for calibration and thus for measurement during pyrolysis process. The reference spectra are acquired for each pure gas compounds in these conditions at different concentrations in nitrogen: $100 \%, 50$ vol. $\%, 25$ vol.\%,10 vol.\% and 5 vol.\%. The TQ Analyst software is used with a CLS method (Classical Least Squares) to get the calibration line of each species. Then,

one or more absorption areas (in wavenumber) are selected for each compound. The 
following bands have been selected to minimize interferences between species:

- methane $1304-1308 \mathrm{~cm}^{-1}$

- ethane $821-823 \mathrm{~cm}^{-1}$ and $1529-1532 \mathrm{~cm}^{-1}$

- $\quad$ propane $2883-2889 \mathrm{~cm}^{-1}$

- ethylene $2043-2049 \mathrm{~cm}^{-1}$ and $1886-1890 \mathrm{~cm}^{-1}$

- propylene $1647-1652 \mathrm{~cm}^{-1}$ and $2963-2971 \mathrm{~cm}^{-1}$

Calibration lines are obtained after selection of these zones. The correlation coefficients given by the present method are 0.99630 for methane, 0.99974 for ethylene, 0.99762 for ethane, 0.99793 for propylene and 0.99583 for propane. The quantification will now be automatic through the use of available software.

\section{Validation of the method under steady-state conditions}

\subsection{Offline validation with gaseous hydrocarbon calibrated mixtures}

Three calibrated gas mixtures furnished by Air Liquide (Table 4) are used to validate the FTIR method under static conditions (no connection to the pyrolysis bench). The presence of acetylene in these mixtures is due to the fact that it is important to determine the effect of unconsidered species on the quantification of the five others. During the pyrolysis, numerous compounds will be produced and several will reach the gas cell, in addition to the five considered ones. Thus, it is necessary to determine the effect of unconsidered species on the quantification. The acetylene interacts with methane in the range $1250-1320 \mathrm{~cm}^{-1}$. As a consequence, the methane amount could be overestimated due to this compound.

\section{Table 4 should be placed here}

The mean relative error found for methane with the three calibrated mixtures is around $16 \%$ (Table 5). This is less than the one determined for propane -about $30 \%$ - $(6 \%$ for ethylene, $2.5 \%$ for ethane, $4 \%$ for propylene). A very high discrepancy is found for ethane in 
the first mixture but this is attributed to the very low absolute ethane quantity in the mixture ( 2 mol.\%). This is confirmed for all the compounds. Of course, the uncertainties are generally high in comparison to an accurate GC-MS apparatus but the aim of this study is to characterise the chemical composition with one measure per $10 \mathrm{~s}$, an accuracy less than 5 mol. $\%$ for main products and a quantification of at least 75 mol. $\%$ of the mixture. This goal is generally reached for methane in the first mixture. The large acetylene content which is found in the calibrated gas mixture furnished by Air Liquide (Table 4) is judged to be responsible for this discrepancy. Nevertheless in the pyrolysis process, this compound never overpassed 1 mol.\% [8]-[10]. Thus, the errors found for methane in the second mixture and all the more in the third one are acceptable (Table 5). The decrease of relative error with the mole fraction increase is satisfactory because this means the uncertainty will be lower in pyrolysis mixture quantification conditions. A discrepancy of 2 mol.\%, for example, corresponds to a high relative error for low concentration than for high one. This is expressed on Figure 2 (all fluids and mixtures are noted), which shows that almost all of the quantification results by FTIR respect the criterion of 5 mol. $\%$ and most present absolute errors less than 2 mol.\%.

\section{Table 5 should be placed here}

\section{Figure 2 should be placed here}

\subsection{Online validation with GC data on gaseous pyrolysis products at the process outlet}

The pyrolysis tests are conducted as follows. The pressure and mass flow rate are fixed and temperature is increased with successive steps of $50 \mathrm{~K}$ to $100 \mathrm{~K}$. When the temperature is stabilised in the system (isothermal plateau), sampling is made on gas and liquid phase for later GC-MS analysis. Then, the temperature set point of the oven is increased. During the entire pyrolysis experiment (generally about eight hours), the gas phase of pyrolysis products is analysed by FTIR through the Series application (real time acquisition) of OMNIC software. The comparison of FTIR and GC-MS data is done for steady-state conditions and 
similar time of sampling and measure. This has been done for all the fuels which have been presented in the section 1.2 with the following test conditions: Titanium reactor, $6 \mathrm{MPa}$, 0.1 g.s $\mathrm{s}^{-1}, 823 \mathrm{~K}$ to $1023 \mathrm{~K}$.

An example is given for n-dodecane pyrolysis (Titanium reactor, $6 \mathrm{MPa}, 0.1$ g.s ${ }^{-1}, 823 \mathrm{~K}$ to $1023 \mathrm{~K}$ by steps of $50 \mathrm{~K}$ ) for which the FTIR raw data is obtained as a function of time (Figure 3a). The FTIR parameters allow one measure every $15 \mathrm{~s}$ (shorter acquisition times will be presented in companion paper [31]). The automatic exploitation of this signal gives the quantification of pyrolysis products as a function of time (Figure $3 b$ ) and thus possibly as a function of temperature, which is measured in the furnace. A very low signal is measured from $0 \mathrm{~s}$ to $7000 \mathrm{~s}$ (furnace temperature set point: $873 \mathrm{~K}$ ). The fluctuations (mostly on the ethane quantification) are not physical and they are due to signal processing. Furthermore, the sum of mole fractions of quantified products tends to unity for higher temperature because of a better dynamic sampling (higher gas production). Around $8000 \mathrm{~s}$ for example (923 K), the sum is about 0.3 , which means theoretically that the quantified products represent only $30 \%$ of the gas phase while $100 \%$ is expected. This difference is due to the filling of the optical gas cell, which is too large (volume of $100 \mathrm{~cm}^{3}$ ) particularly in case of low gas production. This point will be investigated in the companion paper and corrected [31]. Another complementary optical cell will be proposed.

\section{Figure 3 should be placed here}

The comparison between FTIR and GC/MS data is given for four fuels from Table 6 . The chemical compositions are obtained under steady-state conditions for three different temperature levels at $6 \mathrm{MPa}$ and $0.1 \mathrm{~g} \cdot \mathrm{s}^{-1}$, in Titanium reactor. The tests with similar conditions are conducted with several initial fuels (heptane, decane, dodecane, kerosene). The results between GC-MS and FTIR apparatus are similar and a maximum discrepancy around 5 mol. $\%$ is found. Concerning $\mathrm{n}$-heptane, the maximum disagreement is obtained for 
propylene (relative error up to $38 \%$ at $1001 \mathrm{~K}$ ). The relative uncertainty decreases for all the initial fuels and products when increasing the process temperature (increase of gas formation). On the other hand, the quantification by FTIR is not relevant for low mole fraction because the signal can even be negative, which is not physical (Table 6). For n-decane pyrolysis, the propylene and propane signals present the highest discrepancies (Table 6). The absolute error can even reach $11 \mathrm{~mol} \%$ at $997 \mathrm{~K}$ for propane. This is attributed to unaccounted species (acetylene or saturated vapour of liquid species under ambient conditions). In particular, propane is quantified in the range $2800 \mathrm{~cm}^{-1}-2950 \mathrm{~cm}^{-1}$ (vibration of $\mathrm{C}-\mathrm{H}$ bond), which is common for most other hydrocarbons. All the heavier alkenes (quantified by GC/MS in the gas phase from methane to n-heptane) represent $10.72 \mathrm{~mol} \%$ and all the heavier alkanes $7.35 \mathrm{~mol} . \%$. Their sum (about $18 \mathrm{~mol} . \%$ ) is quite close to the over-estimation of FTIR signal (around $21 \mathrm{~mol} . \%$ ). The effect of unconsidered species will be detailed in section 3.3.

The over-estimation of propane by FTIR reaches 8.7 mol.\% for n-dodecane at $1007 \mathrm{~K}$ (Table 6). The same observations as for n-heptane and n-decane can be done for n-dodecane. The total FTIR overestimation is about $26.5 \mathrm{~mol} . \%$ while the other alkene and alkane species found by GC/MS up to heptane are 24.9 mol.\%, which is very close. Furthermore, only one value for each thermal step is available with GC/MS apparatus while several are available with FTIR (transient acquisition). Consequently, it is possible to plot the extreme values measured by FTIR (in dashed line on Figure 4) and to compare them as a function of temperature with GC/MS data (Figure 4). The GC/MS data are in the range of minimum and maximum FTIR data, which is reasonable when put in balance with the difference in measurement times (steady-state compared to transient optical acquisition). The agreement is judged to be very satisfactory because GC/MS measurements are not absolute, due to the variations of the chemical composition at the bench outlet (oscillations of test parameters such as the pressure or mass flow rate). The results obtained with kerosene (Table 6) confirm the 
preceding observation. The overestimation by FTIR $(9.0 \mathrm{~mol} . \%)$ is of the order of the amount of species measured by GC/MS up to heptane (10.3 mol.\%).

The quantification of hydrocarbons by FTIR method is difficult because of the technology itself. The identification of alkanes is more difficult than alkenes because they do not present specificity such as the double $\mathrm{C}=\mathrm{C}$ bond. The method could be improved by using a better optical resolution $\left(0.1 \mathrm{~cm}^{-1}\right.$ instead of $\left.0.5 \mathrm{~cm}^{-1}\right)$, by increasing the number of wave length used to identify and to quantify each species and the number of scans to get a better signal. Unfortunately, this would decrease the frequency of measure and a choice must be done between accuracy and time of acquisition. This is a balance between these both aspects. Other parameters also interfere in the signal analysis (additional compounds in the mixture, operating conditions effect).

\section{Table 6 should be placed here}

\section{Figure 4 should be placed here}

\subsection{Interaction with other hydrocarbon species}

Higher uncertainties have been found for the quantification of propylene and propane. The FTIR overestimations have been correlated in the previous section to the non quantified alkene and alkane species (but quantified by GC/MS). The spectra of alkanes (from butane to dodecane) are very similar because they present major absorption ranges, $2700 \mathrm{~cm}^{-1}$ $3100 \mathrm{~cm}^{-1}$ and $1300 \mathrm{~cm}^{-1}-1500 \mathrm{~cm}^{-1}$, due to $\mathrm{C}-\mathrm{H}$ bond stretching and bending, respectively. The quantification regions corresponding to methane, ethylene, ethane, propylene and propane are located on each spectrum to observe possible interference. The propane amount is clearly impacted by the presence of unaccounted species. Methane may also suffer from overestimation in case of other alkanes being present. In case of alkenes characterisation (Figure 5), new absorption bands are observed : $3050 \mathrm{~cm}^{-1}-3200 \mathrm{~cm}^{-1}, 1600 \mathrm{~cm}^{-1}-1700 \mathrm{~cm}^{-1}$ and $850 \mathrm{~cm}^{-1}-1050 \mathrm{~cm}^{-1}$ due to $=\mathrm{C}-\mathrm{H}$ bond stretching of $\mathrm{CH}_{2}$ groups to the double bond, to 
$\mathrm{C}=\mathrm{C}$ stretching and to $=\mathrm{C}-\mathrm{H}$ bond bending of $\mathrm{CH}_{2}$ groups, respectively. Propane is still the major compound impacted by heavier alkenes; so is propylene, to a lesser extent. The other quantified species, except ethylene, are concerned. The cyclic compounds also have an effect on propane mainly while the production of aromatic species (benzene, toluene, xylene, ethylbenzene notably) should strongly impact all the quantified gases. Nevertheless, the production of cyclic and aromatic compounds remains low enough not to modify significantly the FTIR signal and the associated quantification.

\section{Figure 5 should be placed here}

The signals of propylene and propane are sometimes highly overestimated by FTIR. This is notably due to all the species which are not considered in the quantification but which are present in the gas phase, such as saturated vapour of liquid species under ambient conditions. On the basis of this section, it could be assumed that propylene is representative of all the alkenes formed during the pyrolysis of initial fuel and propane of the alkane ones. For the need of the COMPARER project, this is reasonable because all the alkanes for example will present a similar auto-ignition delay (that is to say very high compared to the $0.1 \mathrm{~ms}$ criterion [9]).

\subsection{Estimation of uncertainties and of detection limit}

The relative uncertainties of all the measurements obtained by FTIR, in comparison with GC/MS data, are represented as a function of absolute quantity (Figure 6). Two curves corresponding to absolute mole fraction are given ( 2 mol.\% and 5 mol.\%) to observe the FTIR method uncertainty. Comparing with Figure 2, it is seen that the presence of unknown species decreases the method accuracy which nevertheless remains in the absolute limit of 5 mol.\%. A vertical line corresponding to a detection limit of $4 \mathrm{~mol} . \%$ is also given. It would be preferable not to interpret any quantity below this limit. Nevertheless, this is not really a drawback because the method aims at quantifying the major pyrolysis products. The 
uncertainties can also be plotted as a function of the gas formation rate, which clearly shows that the higher the gas production, the better the accuracy. Again, this is due to the COMPARER test bench (dead volume and transient sampling method) and not to the FTIR method itself.

\section{Figure 6 should be placed here}

Finally, all the uncertainties related to the FTIR method have been quantified. First, the calibrated gas mixtures (in dilution in nitrogen) which served to the calibration of the FTIR method present an uncertainty arising from the pressure sensor used to constitute these mixtures. The quantification is impacted by the temperature and pressure variations in the gas cell ( $1 \mathrm{~K}$ for $373 \mathrm{~K}$ and $1 \mathrm{mbar}$ for an absolute pressure of $50 \mathrm{mbar}$ ). The absorbance measured by FTIR has its own uncertainty and the choice of the quantification range (in wavenumber) for each species also plays a role. The choice of the quantification range is surely the most challenging and important part of the method conception. The quantification uncertainty for each compound can be finally $17 \%$ for methane, $7 \%$ for ethylene, $4 \%$ for ethane, $7 \%$ for propylene and $16 \%$ for propane. These values were obtained considering only the four sources of uncertainty mentioned above, excluding the presence of unknown species. The impact of which varies depending on the species nature and quantity. The test repeatability can also give a good indicator of the method reliability (Table 7). The absolute discrepancies expressed in mol.\% are less than 2 mol.\% which is acceptable since the FTIR method presents many advantages in comparison with GC-MS.

\section{Table 7 should be placed here}

\section{Conclusion}

The management of high speed flights requires a cooling method which can use the fuel as a coolant to take benefit from endothermic pyrolysis. This is a good point for combustion 
purposes (thermal energy converted into chemical one), but it presents the main drawback to modify the chemical composition which has to be known in order to control the engine operation. Despite several analytical tools exist for chemical composition quantification, none seems to be able to give a "real-time" non intrusive measure for on-board application. The FTIR spectrometer is probably one of the fastest techniques but unfortunately it has low quantification ability. Thus, a specific data processing method has been developed, validated and tested to identify and to quantify the chemical species in a mixture of hydrocarbons. A first step has been conducted with the quantification of major gas products (methane, ethane, ethylene, propane and propylene). Specific wavenumber ranges have been identified for each compound to limit their interaction and to decrease the uncertainties. The method has been calibrated with pure gases diluted in nitrogen before validating it with calibrated mixtures. Then, the method has been applied to the gas phase formed at the pyrolysis process outlet. A comparison with GC/MS data has been conducted on the pyrolysis of several synthetic and jet fuels: $n$-heptane, $n$-decane, $n$-dodecane and kerosene, under similar conditions with Titanium reactor (60 bar, 0.1 g.s $\mathrm{s}^{-1}$, up to $1023 \mathrm{~K}$ ). All the GC/MS results are found to be in the range of minimum-maximum FTIR values, which is satisfactory because the GC/MS analysis gives an average value of a possibly fluctuating process (variation of mass flow rate notably).

A detection limit has been shown around 4 mol.\%, above which the FTIR method is applicable. Its uncertainty decreases when increasing the gas production, which is mainly due to the COMPARER bench and not to the method itself. An absolute error of less than 2 mol.\% is generally found, which can correspond to a high relative error in case of low gas quantity. Nevertheless, this is judged to be highly satisfactory for the SCRamjet application because the aim of this measuring technique is to provide quantitative results of composition to "predict" the burning efficiency of products for thrust control. The uncertainty has been determined and it is the highest for methane. Nevertheless, in presence of unaccounted species, propane is 
largely overestimated and propylene is also affected by lesser extent. It is proposed to consider the propane signal as representative of heavier alkanes while the propylene would represent the heavier alkene species. Furthermore, due to the nature of the FTIR apparatus, signal is continuously acquired and processed along the experiments. Not only FTIR data can be compared to GC/MS results under steady-state pyrolysis conditions, but it can also give instantaneous information of the process. This will be developed in the second part of this work, in a companion paper [31].

\section{Acknowledgements}

The present work has been carried out with the contribution of the "Conseil Général du Cher (18)", of Bourges Plus, of the FRED, of the FEDER, of the FSE (European Union Special Funding) and of MBDA-France. The good evolution of the COMPARER project was made possible thanks to the contribution of Y. Parmantier, who is in charge of the project and the coordinator of the "Pôle Capteurs et Automatismes" of Bourges. S. Bernard is acknowledged for his technical help.

\section{References}

[1] R.S. Fry, A Century of Ramjet Propulsion Technology Evolution, J. Prop. Power 20 (January-February (1)) (2004).

[2] C. McClinton, X-43-Scramjet Power Breaks the Hypersonic Barrier Dryden Lectureship in Research for 2006, 44th AIAA Aerospace Sciences Meeting and Exhibit, Reno, Nevada, 9-12 January, 2006, AIAA 2006-1.

[3] E. Andrews, Scramjet development and testing in the United States, 10th AIAA/NALNASDA-ISAS International Space Planes And Hypersonic Systems And Technologies Conference, Kyoto, Japan, 24-27 April, 2001, AIAA 2001-1927.

[4] E. Curran, Scramjet Engines: the First Forty Years, J. Prop. Power 17 (6) (2001) 
[5] M. Bouchez, S. Beyer, PTAH-SOCAR Fuel-Cooled Composite Materials Structure for Dual-Mode Ramjet and Liquid Rocket Engines - 2005 Status, 13th Hypersonics Systems and Technologies Conference, 2005, AIAA-2005-3434.

[6] M. Bouchez, V. Levine, French-Russian Cooperation in High-Speed Air Breathing Propulsion, AIAA International Air and Space Symposium and Exposition: The Next 100 Years, Dayton, Ohio, 14-17 July, 2003, AIAA 2003-2907

[7] E. Daniau, M. Bouchez, O. Herbinet, P.M. Marquaire, N. Gascoin, P. Gillard, Fuel reforming for scramjet thermal management and combustion optimization, 13th AIAA/CIRA International Space Planes and Hypersonics Systems and Technologies Conference, Capua, Italy, 16-20 May, 2005, AIAA 20053403

[8] E. Daniau, M. Bouchez, R. Bounaceur, F. Battin-Leclerc, P.M. Marquaire, R. Fournet, Contribution to scramjet active cooling analysis using n-dodecane decomposition model as a generic endothermique fuel, 12th AIAA International Space Planes and Hypersonic Systems and Technologies, Norfolk, Virginia, 15-19 December, 2003, AIAA- 20036920

[9] N. Gascoin, Etude et mesure de paramètres pertinents dans un écoulement réactif application au refroidissement par endo-carburant d'un superstatoréacteur, Editions Universitaires Européennes, April 2010, ISBN13: 978-6131501074, p. 376.

[10] K.D. Dahm, P.S. Virk, R. Bounaceur, F. Battin-Leclerc, P.M.Marquaire, R. Fournet, E. Daniau, M. Bouchez, Experimental and modelling investigation of the thermal decomposition of n-dodecane, J. Anal. Appl. Pyrol. 71 (2004) 865-881.

[11] N. Gascoin, P. Gillard, S. Bernard, M. Bouchez, Characterisation of coking activity during supercritical hydrocarbon pyrolysis, Fuel Process. Technol. 89 (December (12)) (2008) $1416-1428$.

[12] K.K. Pant, D. Kunzru, Pyrolysis of n-heptane : kinetics and modelling, J. Anal. Appl. Pyrol. 36 (1996) 103-120. 
[13] J.P. Chakraborty, D. Kunzru, High pressure pyrolysis of n-heptane, J. Anal. Appl. Pyrol. 86 (2009) 44-52

[14] Z. Wang, Y. Guo, R. Lin, Effect of triethylamine on the cracking of heptane under a supercritical condition and the kinetic study on the cracking of heptane, Energy Convers. Manage. 49 (2008) 2095-2099.

[15] S. Garner, R. Sivaramakrishnan, K. Brezinsky, The high-pressure pyrolysis of satured and unsatured C7 hydrocarbons, P. Combust. Inst. 32 (2009) 461-467

[16] S.P. Zeppieri, S.D. Klotz, F.L. Dryer, Modeling concepts for larger carbon number alkanes : a partially reduced skeletal mechanism for $\mathrm{n}$-decane oxidation and pyrolysis, $\mathrm{P}$. Combust. Inst. 28 (2000) 1587-1595.

[17] X. Rocourt, I. Sochet, P. Gillard, F. Faubert, P. Dagaut, Detonability of simple and representative components of pyrolysis products of kerosene: pulsed detonation engine application, Shock Waves 14 (2005) 283-291

[18] X. Rocourt, P. Gillard, I. Sochet, D. Piton, A. Prigent, Thermal degradation of two liquid fuels and detonation tests for pulse detonation engine studies, Shock Waves 16 (2007) 233-245

[19] N. Gascoin, P. Gillard, S. Bernard, E. Daniau, M. Bouchez, SFGP 2007 - Pyrolysis of Supercritical Endothermique Fuel : Evaluation for Active Cooling Instrumentation, Int. J. Chem. React. Eng. 6 (2008) A7.

[20] O. Herbinet, P.M. Marquaire, F. Battin-Leclerc, R. Fournet, Thermal decomposition of n-dodecane : Experiments and kinetic modelling, J. Anal. Appl. Pyrol. 78 (March (2)) (2007) 419-429.

[21] J. Yu, S. Eser, Supercritical-phase thermal decomposition of binary mixtures of jet fuel model compounds, Fuel 79 (2000) 759-768. 
[22] Z. Wang, Y. Guo, R. Lin, Pyrolysis of hydrocarbon fuel ZH-100 under different pressures, J. Anal. Appl. Pyrol. 85 (May (1-2)) (2009) 534-538.

[23] G. Abraham, Etude et développement d'une méthode d'analyse par spectroscopie infrarouge appliquée à la pyrolyse d'hydrocarbures en conditions supercritiques et transitoires, Ph.D. Thesis, December 2009, University of Orléans, France

[24] M. Debliquy, Capteurs de gaz à semi-conducteurs, Techniques de l'Ingénieur, September 2006, r2385.

[25] M. Dalibart, L. Servant, Spectroscopie dans l'infrarouge, Techniques de l'Ingénieur, December 2000, p2845.

[26] J. Barbillat, D. Bougeard, G. Buntinx, M. Delhaye, P. Dhamelincourt, F. Fillaux, Spectrométrie Raman, Techniques de l'Ingénieur, September 1999, p2865

[27] J. Vandegans, A.M. Kersabiec, M. Hoenig, Spectrométrie d'absorption atomique, Techniques de l’Ingénieur, March 1997, p2825

[28] D. Di Benedetto, P. Breuil, Spectrophotométrie d'absorption dans l'ultaviolet et le visible, Techniques de l’Ingénieur, March 2007, p2795

[29] C. Descamps, G.L. Vignoles, O. Féron, F. Langlais, J. Lavenac, Correlation between Homogeneous Propane Pyrolysis and Pyrocarbon, J. Electrochem. Soc. 148 (2001) 695-708.

[30] O. Feron, F. Langlais, R. Naslain, In-situ analysis of gas phase decomposition and kinetic study during carbon deposition from mixtures of carbon tetrachloride and methane, Carbon 37 (1999) 1355-1361

[31] N. Gascoin, G. Abraham, P. Gillard, M. Bouchez, Real-time method for the identification and quantification of hydrocarbon pyrolysis products: Part II. Application to transient pyrolysis and validation by numerical simulation, J. Anal. Appl. Pyrol. Companion paper under review. 
Table 1. Quantification of pyrolysis products (mole fraction) found for n-decane pyrolysis.

\begin{tabular}{ccc}
\hline \hline & $\begin{array}{c}\text { Rocourt et al. } \\
{[18]}\end{array}$ & $\begin{array}{c}\text { Zeppieri et al. } \\
{[17]}\end{array}$ \\
\hline Type of reactor & quartz open tubular reactor \\
Residence time (s) & 0.3 & 0.3 \\
Pressure (Mpa) & 0.1 & 0.1 \\
Temperature (K) & 1073 & 1060 \\
Conversion rate & $90 \%$ & $100 \%$ \\
\hline Hydrogen & 11.3 & - \\
Methane & 21 & 10.8 \\
Acetylene & - & 2.3 \\
Ethylene & 52.9 & 63.5 \\
Ethane & - & 4.4 \\
Propylene & 13.7 & 12.7 \\
Propane & - & - \\
1-Butene & - & 3.6 \\
1-Pentene & - & 0 \\
1-Hexene & - & 0 \\
1-3-Butadiene & - & 2.7 \\
Benzene & 0.9 & - \\
n-Decane & 0.2 & 0 \\
\hline \hline
\end{tabular}


Table 2. Quantification of pyrolysis products (mole fraction) found for n-dodecane pyrolysis.

\begin{tabular}{cccc}
\hline \hline & Gascoin et al.[20] & $\begin{array}{c}\text { Herbinet et al. } \\
{[21]}\end{array}$ & Dahm et al. [11] \\
\hline Type of reactor & $\begin{array}{c}\text { Stainless steel open } \\
\text { tubular reactor }\end{array}$ & $\begin{array}{c}\text { Perfectly Stirred } \\
\text { Quartz Reactor }\end{array}$ & $\begin{array}{c}\text { Stainless steel open } \\
\text { tubular reactor }\end{array}$ \\
Dilution & without & 2 vol.\% in He & in N \\
Residence time (s) & $10-200$ & $1-5$ & $0.04-0.2$ \\
Pressure (Mpa) & 1 & 0.1 & 0.1 \\
Temperature (K) & 923 & 873 & 1050 \\
Conversion rate & $45 \%$ & $56 \%$ & $64 \%$ \\
\hline hydrogene & 0.02 & 0.13 & - \\
methane & 0.35 & 0.15 & 0.13 \\
acetylene & 0 & 0.00 & 0.01 \\
ethylene & 0.11 & 0.55 & 0.63 \\
ethane & 0.21 & 0.02 & 0.04 \\
propylene & 0.14 & 0.15 & 0.19 \\
propane & 0.08 & - & - \\
\hline \hline
\end{tabular}


Table 3. Comparison of currently available analytical techniques for chemical quantification.

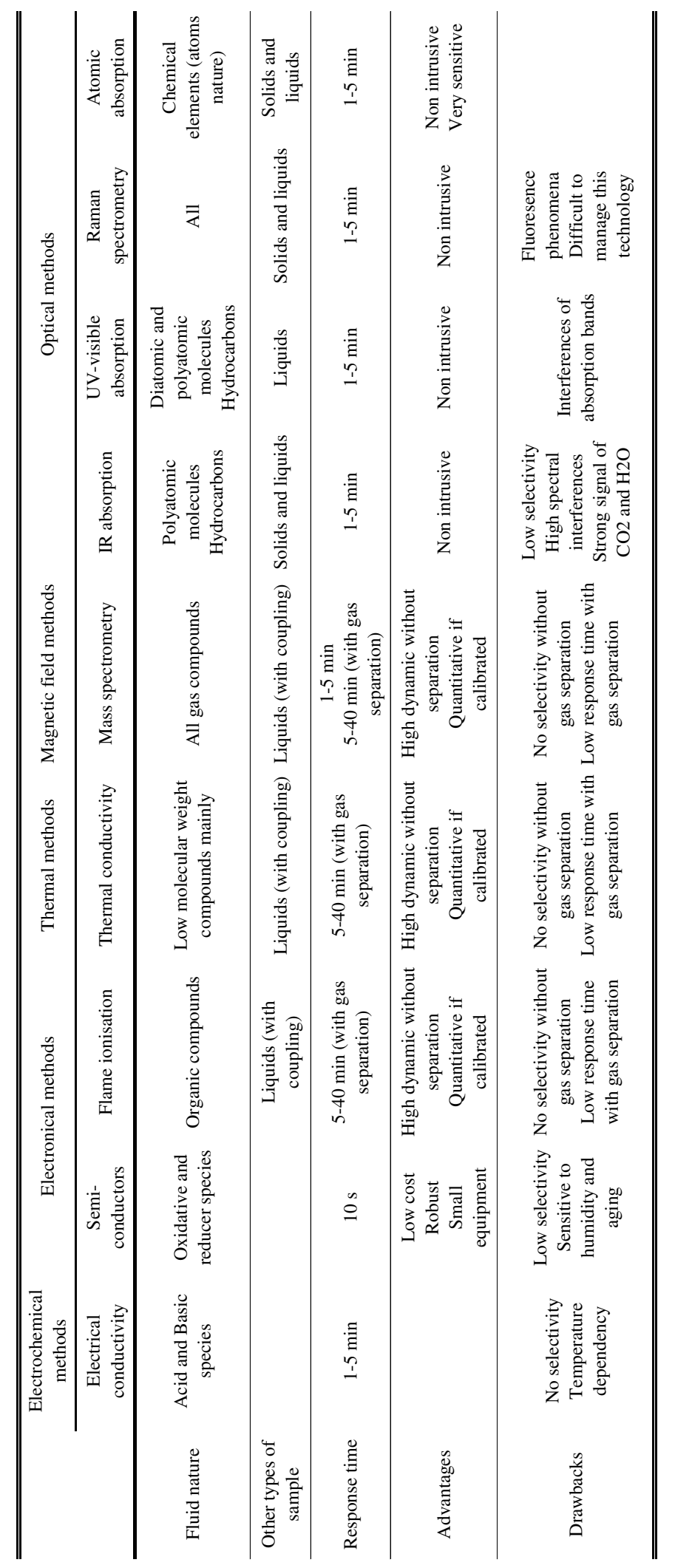


Table 4. Composition and relative uncertainties of calibrated mixtures.

\begin{tabular}{rcccccc}
\hline \hline & \multicolumn{2}{c}{ mixture 1 } & \multicolumn{2}{c}{ mixture 2 } & \multicolumn{2}{c}{ mixture 3 } \\
\cline { 2 - 7 } & mol. \% & $\begin{array}{c}\text { relative } \\
\text { error }\end{array}$ & mol. \% & $\begin{array}{c}\text { relative } \\
\text { error }\end{array}$ & mol. \% & $\begin{array}{c}\text { relative } \\
\text { error }\end{array}$ \\
\cline { 2 - 7 } $\mathrm{H}_{2}$ & 23.52 & 0.02 & 51.32 & - & 4.548 & 0.02 \\
$\mathrm{~N}_{2}$ & - & - & - & - & 7.61 & 0.02 \\
$\mathrm{C}_{2} \mathrm{H}_{2}$ & 9.61 & 0.03 & 4.65 & 0.03 & 1.923 & 0.03 \\
$\mathrm{CH}_{4}$ & 41.455 & - & 19.76 & 0.02 & 4.974 & 0.02 \\
$\mathrm{C}_{2} \mathrm{H}_{4}$ & 5.09 & 0.02 & 9.68 & 0.02 & 41.795 & - \\
$\mathrm{C}_{2} \mathrm{H}_{6}$ & 2.192 & 0.02 & 5.02 & 0.02 & 14.85 & 0.02 \\
$\mathrm{C}_{3} \mathrm{H}_{6}$ & 16.07 & 0.03 & 4.54 & 0.03 & 9.6 & 0.03 \\
$\mathrm{C}_{3} \mathrm{H}_{8}$ & 2.063 & 0.02 & 5.03 & 0.02 & 14.7 & 0.02 \\
\hline \hline
\end{tabular}


Table 5. Comparison of compositions estimated by FTIR to certified compositions for three reference mixtures (all values in mol. \%).

\begin{tabular}{cccccccccc}
\hline \hline & \multicolumn{3}{c}{ mixture 1 } & \multicolumn{3}{c}{ mixture 2 } & \multicolumn{3}{c}{ mixture 3 } \\
\cline { 2 - 9 } & Reference & FTIR & $\begin{array}{c}\text { Relative } \\
\text { error }\end{array}$ & Reference & FTIR & $\begin{array}{c}\text { Relative } \\
\text { error }\end{array}$ & Reference & FTIR & $\begin{array}{c}\text { Relative } \\
\text { error }\end{array}$ \\
\hline $\mathrm{CH}_{4}$ & 41.455 & 48.18 & $16.2 \%$ & 19.76 & 23.01 & $16.4 \%$ & 4.974 & 4.19 & $15.8 \%$ \\
$\mathrm{C}_{2} \mathrm{H}_{4}$ & 5.09 & 5.31 & $4.3 \%$ & 9.68 & 10.34 & $6.8 \%$ & 41.795 & 39.15 & $6.3 \%$ \\
$\mathrm{C}_{2} \mathrm{H}_{6}$ & 2.192 & 5.29 & $141.3 \%$ & 5.02 & 4.96 & $1.2 \%$ & 14.85 & 15.44 & $4.0 \%$ \\
$\mathrm{C}_{3} \mathrm{H}_{6}$ & 16.07 & 15.89 & $1.1 \%$ & 4.54 & 4.66 & $2.6 \%$ & 9.6 & 8.97 & $6.6 \%$ \\
$\mathrm{C}_{3} \mathrm{H}_{8}$ & 2.063 & 0.83 & $59.8 \%$ & 5.03 & 5.83 & $15.9 \%$ & 14.7 & 16.78 & $14.1 \%$ \\
\hline \hline
\end{tabular}


Table 6. Comparison of FTIR measurements with steady-state GC/MS data for four fuel pyrolysis products quantification (all values in mol. \%).

\begin{tabular}{|c|c|c|c|c|c|c|c|c|c|c|c|}
\hline \multirow{2}{*}{ Fuel } & \multirow{2}{*}{$\begin{array}{c}\text { Temperature } \\
(\mathrm{K})\end{array}$} & \multicolumn{2}{|c|}{$\mathrm{CH}_{4}$} & \multicolumn{2}{|c|}{$\mathrm{C}_{2} \mathrm{H}_{4}$} & \multicolumn{2}{|c|}{$\mathrm{C}_{2} \mathrm{H}_{6}$} & \multicolumn{2}{|c|}{$\mathrm{C}_{3} \mathrm{H}_{6}$} & \multicolumn{2}{|c|}{$\mathrm{C}_{3} \mathrm{H}_{8}$} \\
\hline & & GC/MS & FTIR & GC/MS & FTIR & GC/MS & FTIR & GC/MS & FTIR & GC/MS & FTIR \\
\hline \multirow{3}{*}{ n-Heptane } & 868 & 4.17 & 0.47 & 0.81 & -0.32 & 5.70 & 3.79 & 1.87 & 5.72 & 2.13 & -0.74 \\
\hline & 960 & 22.62 & 19.24 & 18.61 & 13.28 & 21.21 & 23.22 & 11.80 & 18.96 & 7.41 & 9.07 \\
\hline & 1001 & 9.45 & 14.27 & 17.54 & 18.65 & 20.97 & 25.40 & 18.70 & 25.97 & 11.53 & 14.50 \\
\hline \multirow{3}{*}{ n-Decane } & 808 & 0.00 & 0.17 & 0.00 & 0.03 & 0.00 & -0.70 & 0.00 & -1.23 & 0.00 & -0.01 \\
\hline & 903 & 0.66 & -0.03 & 0.57 & -0.06 & 0.97 & 1.77 & 0.20 & 0.70 & 0.41 & 0.61 \\
\hline & 997 & 16.26 & 13.12 & 14.60 & 15.14 & 22.43 & 26.77 & 16.18 & 21.17 & 12.66 & 23.76 \\
\hline \multirow{5}{*}{ n-Dodecane } & 818 & 0.00 & -0.43 & 0.00 & -0.18 & 0.40 & 1.21 & 0.00 & -0.76 & 0.32 & 0.14 \\
\hline & 867 & 0.00 & -0.37 & 0.00 & -0.28 & 0.50 & 0.37 & 0.06 & -1.10 & 0.36 & 0.21 \\
\hline & 916 & 4.16 & 2.60 & 2.78 & 2.99 & 7.80 & 9.53 & 4.29 & 5.09 & 4.61 & 6.91 \\
\hline & 960 & 13.26 & 15.17 & 10.60 & 13.04 & 23.98 & 28.69 & 17.25 & 20.92 & 17.33 & 27.72 \\
\hline & 1007 & 16.29 & 21.15 & 11.07 & 14.69 & 20.27 & 25.32 & 17.29 & 21.60 & 15.19 & 23.94 \\
\hline \multirow{3}{*}{ Kerosene } & 805 & 0.04 & -0.07 & 0.38 & -0.13 & 0.44 & 0.10 & 0.05 & -1.89 & 0.32 & 0.00 \\
\hline & 893 & 0.26 & 0.40 & 0.00 & 0.05 & 0.41 & -0.71 & 0.04 & -1.88 & 0.30 & 0.20 \\
\hline & 984 & 34.01 & 29.49 & 10.74 & 11.54 & 20.46 & 20.56 & 12.37 & 14.29 & 10.70 & 16.88 \\
\hline
\end{tabular}


Table 7. Estimation of test repeatability on the quantification of the five major gas compounds.

\begin{tabular}{|c|c|c|c|c|c|c|}
\hline & \multicolumn{4}{|c|}{ Molar fraction $(\%)$} & \multirow{2}{*}{$\begin{array}{l}\text { Mean molar } \\
\text { fraction }(\%)\end{array}$} & \multirow{2}{*}{$\begin{array}{c}\text { Mean discrepancy } \\
(\mathrm{mol} . \%)\end{array}$} \\
\hline $\mathrm{CH} 4$ & 4.07 & 4.19 & 3.63 & 4.32 & & \\
\hline $\mathrm{C} 2 \mathrm{H} 4$ & 39.70 & 39.15 & 39.81 & 43.68 & 40.59 & 1.55 \\
\hline $\mathrm{C} 2 \mathrm{H} 6$ & 16.55 & 15.44 & 14.22 & 16.93 & 15.79 & 0.96 \\
\hline C3H6 & 9.88 & 8.97 & 10.13 & 10.32 & 9.83 & 0.43 \\
\hline $\mathrm{C} 3 \mathrm{H} 8$ & 16.90 & 16.78 & 16.84 & 18.55 & 17.27 & 0.64 \\
\hline Test number & 1 & 2 & 3 & 4 & & \\
\hline
\end{tabular}




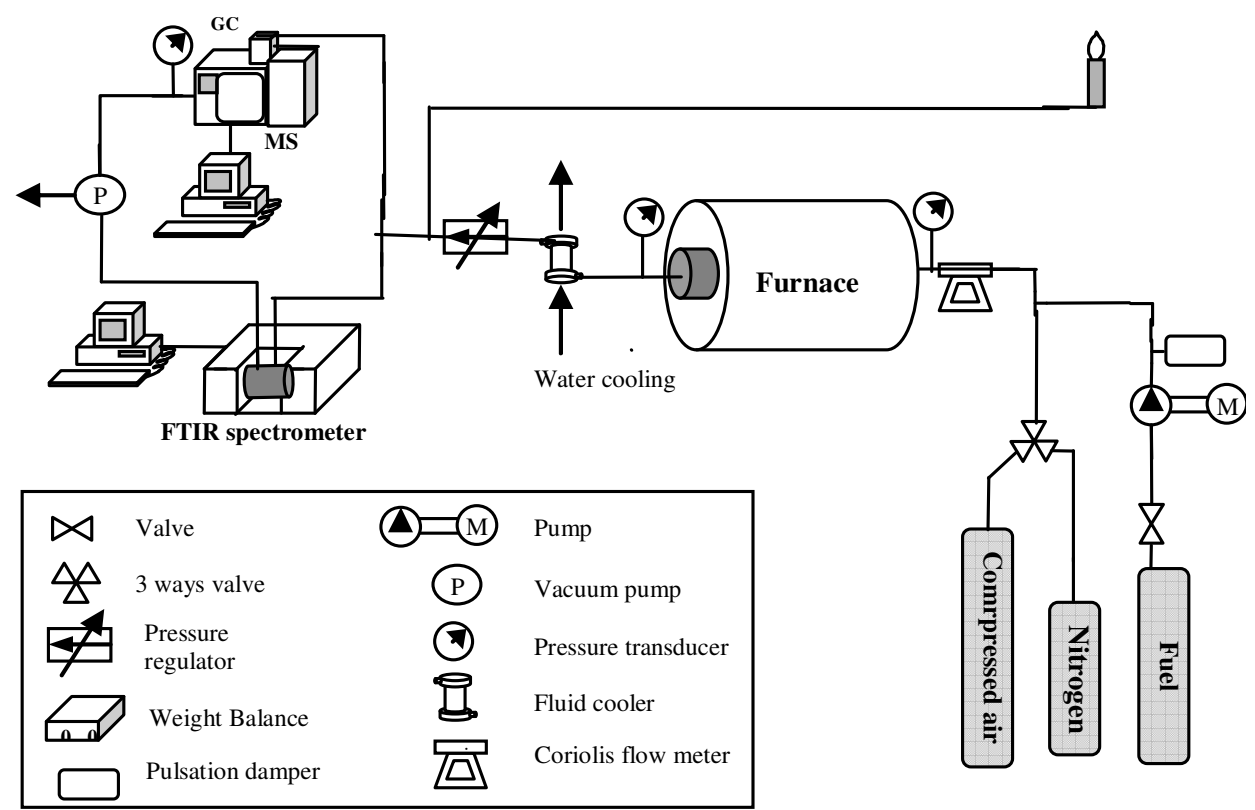

Figure 1. Schematic of the COMPARER-2 test bench with FTIR and GC-MS analysis. 


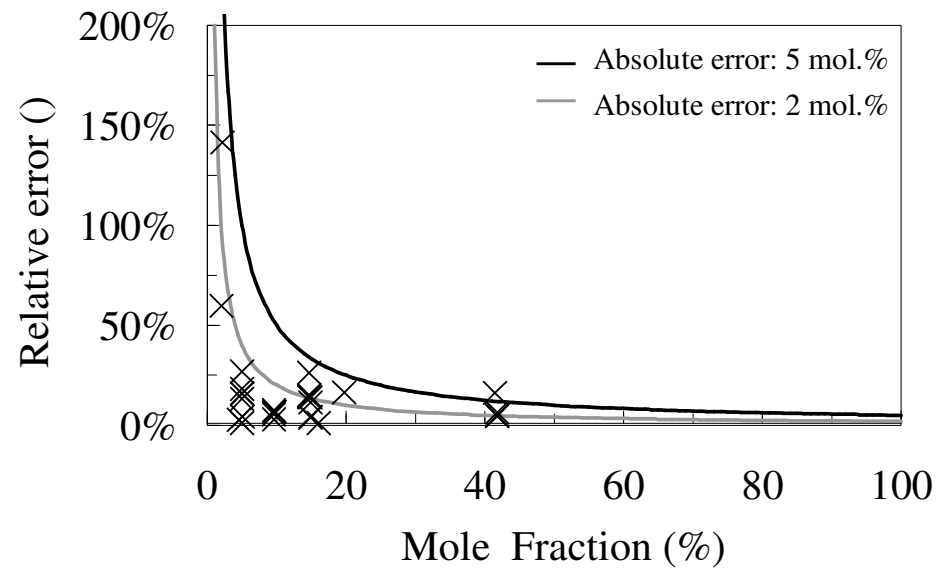

Figure 2. Relative error as a function of concentration with theoretical curves giving relative error as a function of absolute error (static tests at 1.1 bar and $298 \mathrm{~K}$ with calibrated mixtures). 

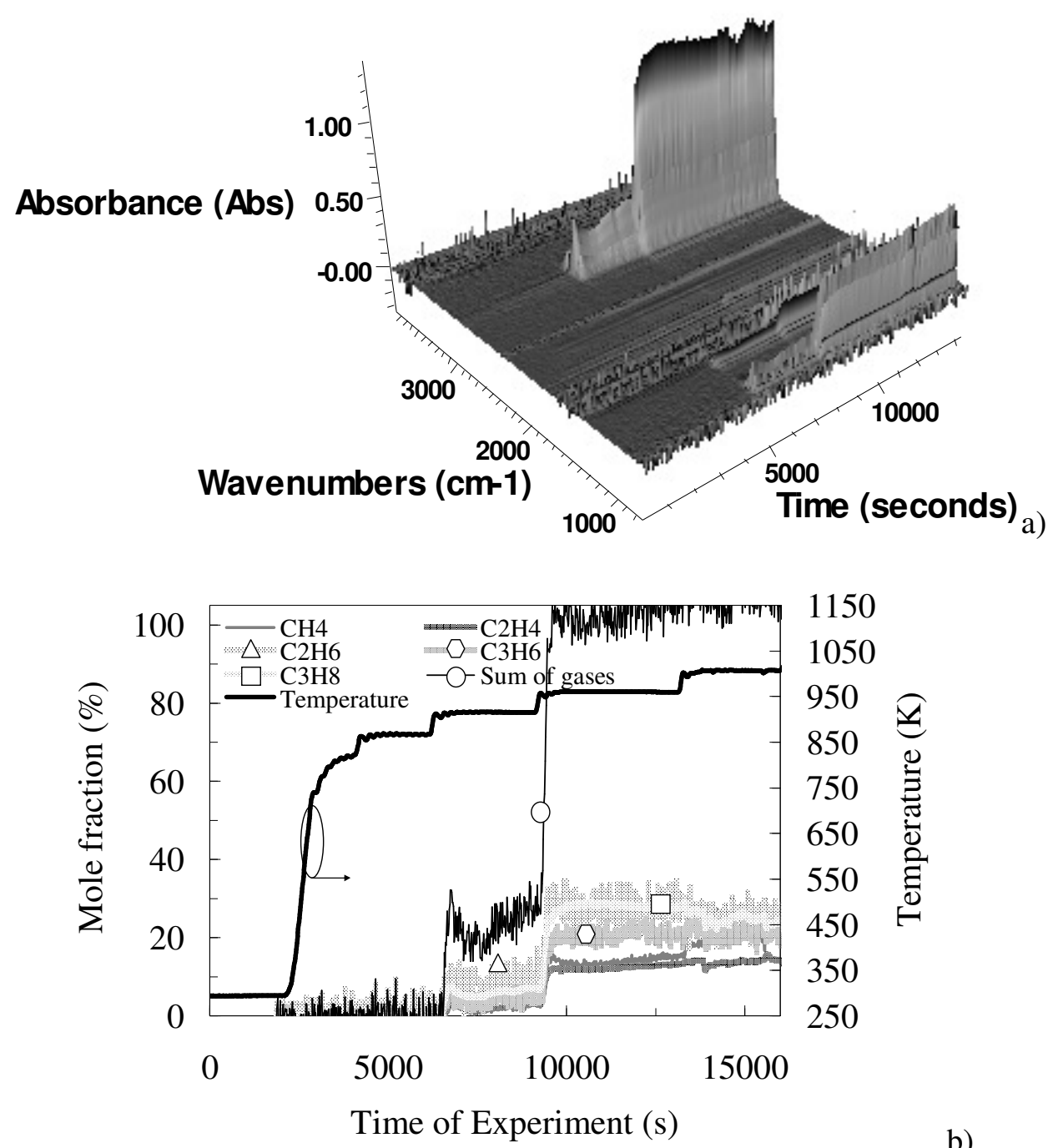

1150

1050

950

850 ช

750

650

550

450

350

250

Time of Experiment (s)

b)

Figure 3. Raw FTIR signal during n-dodecane pyrolysis test (a) and maximum furnace temperature and transient mole fraction of gas species during the experiment (b). 

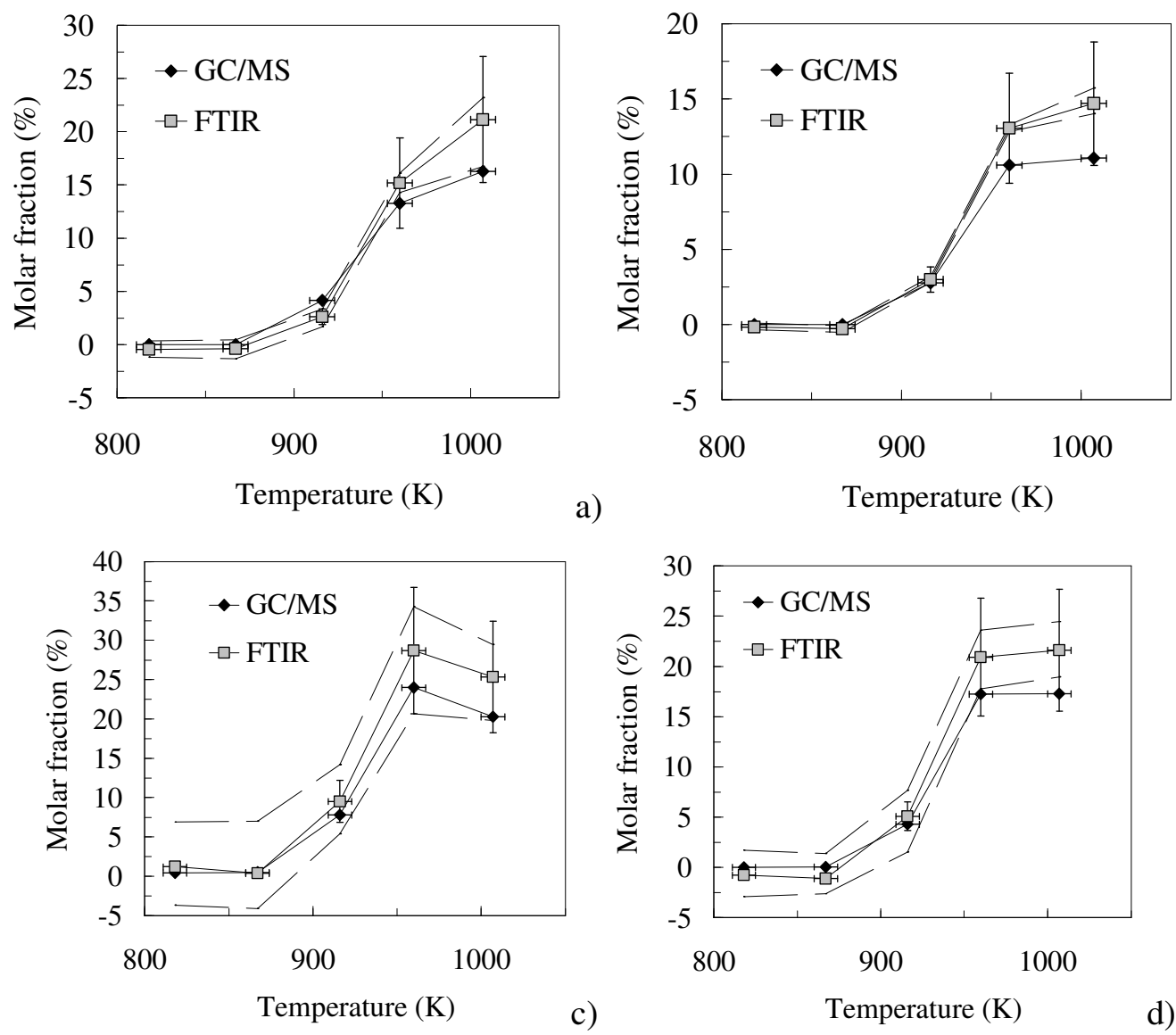

b)

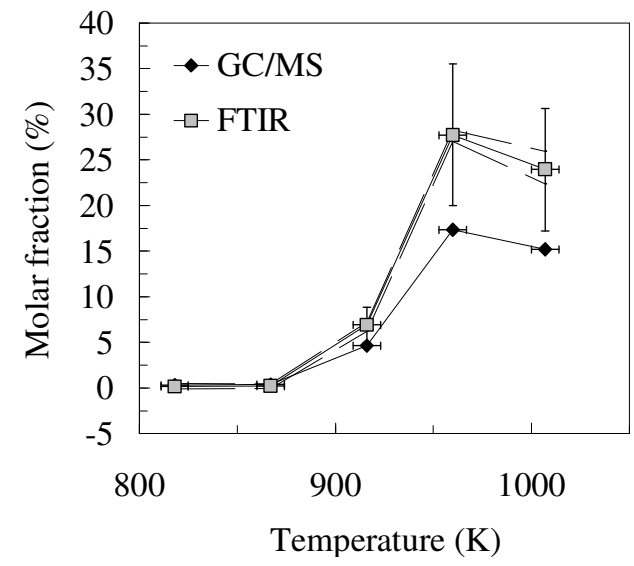

e)

Figure 4. Quantification of methane (a), ethylene (b), ethane (c), propylene (d) and propane (e) as a function of temperature by GC/MS and with FTIR (min and max values) during n-dodecane pyrolysis. 


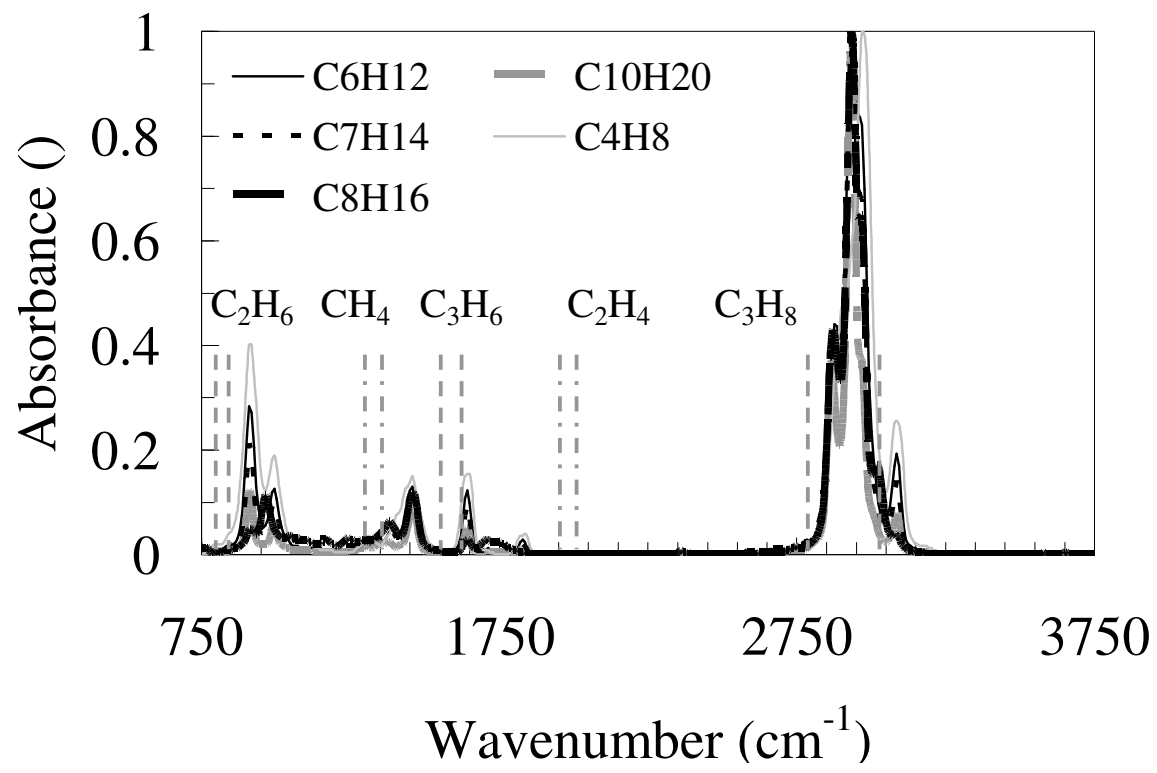

Figure 5. Normal Alkenes spectra with interaction on acquisition range of quantified gases. 


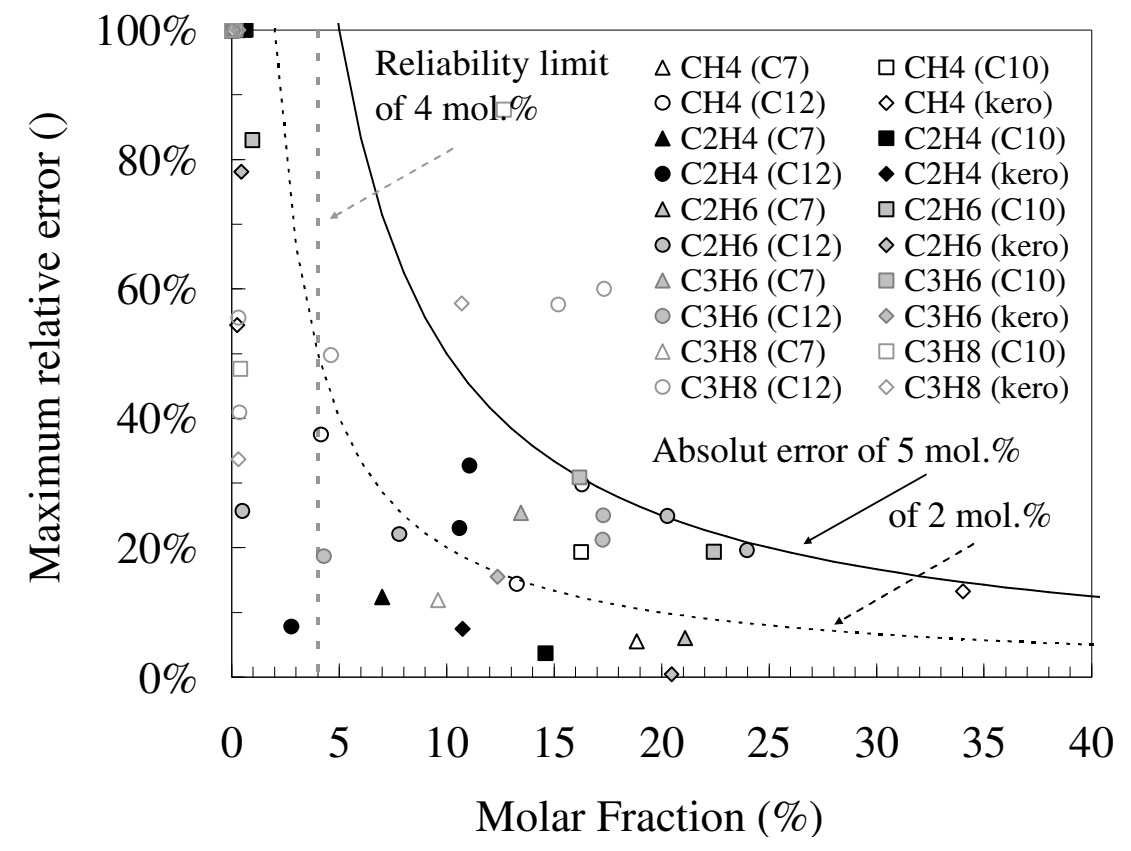

Figure 6. Relative uncertainties of FTIR quantification method compared to GC/MS data as a function of absolute mole fraction. 